\title{
A Normalization Scheme of Bidirectional Reflectances and Normalized Vegetation Indices for Short-Term Multi-Angular Spot Satellite Images
}

Chien-Hui Liu

Department of Information Management, Transworld Institute of Technology, Douliu, Yunlin, Taiwan 64045., chliu@tit.edu.tw

Follow this and additional works at: https://jmstt.ntou.edu.tw/journal

Part of the Electrical and Computer Engineering Commons

\section{Recommended Citation}

Liu, Chien-Hui (2003) "A Normalization Scheme of Bidirectional Reflectances and Normalized Vegetation Indices for Short-Term Multi-Angular Spot Satellite Images," Journal of Marine Science and Technology. Vol. 11: Iss. 4, Article 4. DOI: $10.51400 / 2709-6998.2291$

Available at: https://jmstt.ntou.edu.tw/journal/vol11/iss4/4

This Research Article is brought to you for free and open access by Journal of Marine Science and Technology. It has been accepted for inclusion in Journal of Marine Science and Technology by an authorized editor of Journal of Marine Science and Technology. 
A Normalization Scheme of Bidirectional Reflectances and Normalized Vegetation Indices for Short-Term Multi-Angular Spot Satellite Images

Acknowledgements

This study was financially supported by the National Science Council of the Republic of China (grant No. NSC91-2212-E-265-001). 


\title{
A NORMALIZATION SCHEME OF BIDIREC- TIONAL REFLECTANCES AND NORMALIZED VEGETATION INDICES FOR SHORT-TERM MULTI-ANGULAR SPOT SATELLITE IMAGES
}

\author{
Chien-Hui Liu
}

Key words: SPOT, normalization, bidirectional reflectances, vegetation index.

\section{ABSTRACT}

Though the view angle range of SPOT HRV is smaller as compared to those of NOAA AVHRR, EOS MODIS/MISR and ADEOS POLDER, numerous researchers had showed significant bi-directional effect of ground reflectance for decades. Currently, there's no existing normalization method of bidirectional reflectances for multitemporal SPOT images. In this study, a normalization scheme for multi-angular SPOT data is proposed. This scheme will correct both atmospheric and bidirectional effect for short-term multi-temporal SPOT data. Five SPOT images scanned within twelve days are used. The results show that the variation of trees reflectance to viewing zenith angle is very significant. The proposed normalization scheme can satisfactorily correct viewing zenith angle effect of bidirectional reflectances of trees. Normalized vegetation indices are also developed and successfully shown to reduce the viewing angle effect of Normalized Difference Vegetation Index (NDVI). Soil Adjusted Vegetation Index (SAVI) is found to be less dependent on viewing zenith angle than NDVI and normalized VIs in the azimuthal plane away from the principal plane. This may be due to the effectiveness of SAVI in the reduction of viewing zenith angle effect induced by the soil and shadow and the error of the atmospheric correction model.

\section{INTRODUCTION}

It has been widely known that satellite remote sensing plays a key role in monitoring regional or global terrestrial vegetation (Huete et al., 1999). Quantitative analysis of satellite images for vegetation monitoring should rely on accurate evaluation of sensor calibration drifts, cloud screening, atmospheric effect and variation in sun-target-sensor geometry (Leroy and Roujean, 1994). Due to the anisotropic characteristics of surfaces

Paper Submitted 08/29/03, Accepted 11/24/03. Author for Correspondence: Chien-Hui Liu.

*Department of Information Management, Transworld Institute of Technology, Douliu, Yunlin, Taiwan 64045.

E-mail: chliu@tit.edu.tw.
(Deering et al., 1992), surface bidirectional reflectances derived from multi-temporal and multi-angular satellite images by atmospheric correction model show significant bidirectional effect and should be further normalized to a standard sun-target-sensor geometry (termed "normalized reflectance" here) in order to monitor terrestrial vegetation on regional or global scales (Leroy and Roujean, 1994; Asner et al. 1998; Duchemin et al., 2002). Vegetation indices, designed to enhance the vegetation information against the external factors such as atmosphere, soil, sun-target-sensor geometry, are widely used to infer ecosystem and biophysical parameters as excellently reviewed by Asner et al. (1998), Huete et al. (1999) and should also be normalized to improve the consistency with surface properties (Hu et al., 2000). The necessity of considering bidirectional effect for land surface studies has also increasingly been recognized, for example, land cover classification (Wanner et al., 1997). Normalized reflectance is termed as bidirectional reflectance for nadir view at the nominal sun angle (Strahler et al., 1996). It is used as input for Earth Observing System (EOS) MODerate resolution Imaging Spectroradiometer (MODIS) land cover product. Accordingly, normalization of multi-angular satellite data is necessary.

Several researchers have used bidirectional reflectance models, including empirical, semi-empirical and physical models (Lucht and Lewis, 2000; Kalluri et al., 2001), to normalize bidirectional reflectances derived from multi-temporal and multi-angular remotely sensed data. To determine which model to be implemented one has to take into account the objective of the applications such as retrieval of either Leaf Area Index (LAI) or surface albedo. An empirical model, e.g. Walthall model (Walthall et al., 1985), cannot be used to infer physical parameters such as LAI, whereas it can be well suited to compute surface albedo (Kalluri et al., 2001). Although physical model can be applied to derive some surface characteristics, e.g. the size, shape and distribu- 
tion of vegetation canopy elements, extensive computation and large number of parameters may hinder the application. Kalluri et al. (2001) indicated that it is necessary to use high performance computing methodology to accelerate the inversion of complex, non-linear physical model to obtain the surface parameters. Semiempirical approaches can, therefore, have the advantages of easiness and speed to model the bidirectional reflectance of vegetation. These semi-empirical models include the kernel-driven models such as the Algorithm for Modis Bidirectional Reflectance Anisotropies of the Land Surface (Ambrals) Bidirectional Reflectance Distribution Function (BRDF) model (Wanner et $a l .$, 1997), which is used to generate BRDF datasets derived from MODIS on EOS, and the Roujean model (Roujean et al., 1992) used to generate BRDF dataset derived from POLarization and Directionality of the Earth's Radiation (POLDER) instrument on ADvanced Earth Observing Satellite-I (ADEOS-I).

Although several bidirectional reflectance models have already been widely developed and applied to normalize the bidirectional reflectances or vegetation indices for National Oceanic and Atmospheric Administration (NOAA) Advanced Very High Resolution Radiometers (AVHRR) (Leroy and Roujean, 1994; Hu et al., 2000; Kalluri et al., 2001), EOS MODIS and Multiangle Imaging SpectroRadiometer (MISR) (Wanner et al., 1997; Lucht and Lewis, 2000), Systeme Probatoire d'Observation de la Terre (SPOT) VEGETATION (Duchemin et al., 2002) and ADEOS POLDER (Leroy and Hautecoeur, 1999) images, a scheme to normalize the bidirectional reflectances of multi-temporal and multi-angular SPOT High Resolution Visible (HRV) high resolution images has not been proposed by using bidirectional reflectance model. The reasons may be due to inadequate data of images viewed at different angles to permit fitting of a bidirectional reflectance model for a given period, and smaller view angle compared with the AVHRR, MODIS/MISR, VEGETATION and POLDER. However, a few researchers (Verbrugghe and Cierniewski, 1995; Epiphanio and Huete, 1995) also show significant variations of bidirectional reflectances, Normalized Difference Vegetation Index (NDVI) and Soil Adjusted Vegetation Index (SAVI) for SPOT view angle ranges, which implies the importance of the normalization of multi-angular SPOT data.

SPOT HRV data, including multi-spectral bands: XS1 (green), XS2 (red) and XS3 (near-infrared), have been widely applied in various fields such as river monitoring and management (Gupta et al., 2002), vegetation mapping (Nilsen et al., 1999), identification of forest ecosystems (Ustin and Xiao, 2001) and crop mapping (Turner and Congalton, 1998). Raw SPOT images are usually used for these applications by disregarding atmospheric and bidirectional effects. Therefore, the normalization of multi-temporal and multi-angular SPOT HRV data can potentially explore more quantitative applications to complement the use of AVHRR, MODIS/MISR, VEGETATION and POLDER data for regional studies. As a matter of fact, it has been crucial for precision farming study in the complex land use of Taiwan (Liu et al., 2001).

This paper proposes to develop a scheme to normalize the bidirectional reflectances of the multiangular SPOT data. Normalized vegetation indices defined by the normalized reflectances are proposed. Sensitivities of vegetation indices such as NDVI and SAVI with or without being normalized to viewing angle effect are also studied. It should be noticed that this paper focuses on the study of the normalization of short-term (e.g. twelve days) multi-angular SPOT data. In the near future, studies of the normalization of longterm (e.g. annual) multi-temporal SPOT data will be undertaken.

\section{MATERIALS AND METHODS}

A normalization scheme of bidirectional reflectances for multi-angular SPOT satellite images is presented in this section. It contains three steps: (1) atmospheric correction; (2) modeling of bidirectional reflectances; (3) normalization of bidirectional reflectances. Details of every step are described in the following sub-sections. In addition, the normalized vegetation indices are also developed and the bidirectional SPOT satellite images dataset are described.

\section{Algorithm of Retrieval of Aerosol Optical Depth and Surface Reflectances}

Since aerosol concentration is highly changed in space and time, the conventional method, using a unique aerosol optical depth (AOD) (e.g. 0.2 in $550 \mathrm{~nm}$ ) applied in the atmospheric correction of multi-temporal remotely sensed data such as the study of $\mathrm{Hu}$ et al. (2000), is not suitable. In this research, a Blockwise approach to Atmospheric Correction Model (BACM) is used to correct the non-uniform atmospheric effect and retrieve the surface reflectance from satellite images such as SPOT HRV and Landsat Thematic Mapper (TM) (Liu and Vermote, 2000; Liu and Lin, 2003). BACM retrieves AOD with satisfactory accuracy by using dense dark vegetation targets from the image itself. Therefore, it is more suitable than the aforementioned conventional method. The accuracy of BACM to retrieve AOD and surface reflectance had been conducted in the previous studies (Liu et al., 2001). The 
simultaneous AOD measurements by sunphotometer located in National Central University of Taiwan (NCU_Taiwan) of AErosol RObotic NETwork (AERONET) (Holben et al., 1998) were implemented to test the algorithm. The root-mean-square-errors (RMSE) of retrieved AOD were 0.12 and 0.08 in XS1 and XS2 bands, respectively. The accuracy of BACM to retrieve surface reflectance was also evaluated by comparison of atmospheric corrected surface reflectance and spectroradiometer measurements for rice field in precision farming project (Liu et al., 2001). Before atmospheric correction, the RMSE of rice reflectance was 0.089, and it was reduced to 0.04 after correction for all XS bands over the reflectance range $0.03 \sim 0.39$. Therefore, one can see that BACM are quite satisfactory.

Due to the anisotropic characteristics of natural surface, the retrieved surface reflectances are both functions of solar and viewing directions, therefore, they are usually called bidirectional reflectances. To determine the bidirectional effect of vegetation, the bidirectional reflectances are necessary to be modeled or parameterized. In the following section, a semi-empirical model used to model the bidirectional reflectance for vegetation is presented.

\section{Modeling of bidirectional reflectances for vegetation}

A linear kernel-driven model with three parameters developed by Roujean et al. (1992) is used to parameterize the bidirectional reflectance for vegetation. The bidirectional reflectance model can be written as follows:

$$
\begin{aligned}
\rho\left(\theta_{s}, \theta_{v}, \phi\right) & =k_{0}+k_{1} f_{1}\left(\theta_{s}, \theta_{v}, \phi\right)+k_{2} f_{2}\left(\theta_{s}, \theta_{v}, \phi\right) \\
f_{1}\left(\theta_{s}, \theta_{v}, \phi\right) & =[(\pi-\phi) \cos \phi+\sin \phi] \tan \theta_{s} \tan \theta_{v} /(2 \pi) \\
- & {\left[\tan \theta_{s}+\tan \theta_{v}+\operatorname{sqrt}\left(\tan ^{2} \theta_{s}+\tan ^{2} \theta_{v}\right.\right.} \\
- & \left.\left.2 \tan \theta_{s} \tan \theta_{v} \cos \phi\right)\right] / \pi \\
f_{2}\left(\theta_{s}, \theta_{v}, \phi\right) & =\left[1 /\left(\cos \theta_{s}+\cos \theta_{v}\right][4 /(3 \pi)]\right. \\
\bullet & {[(\pi / 2-\xi) \cos \xi+\sin \xi]-1 / 3 }
\end{aligned}
$$

where $\theta_{s}, \theta_{v}, \phi$ are the solar zenith angle, viewing zenith angle and relative azimuth angle, respectively; $\cos \xi=$ $\cos \theta_{s} \cos \theta_{v}+\sin \theta_{s} \sin \theta_{v} \cos \phi ; k_{0}$ is the bidirectional reflectance for $\theta_{s}=\theta_{v}=0, k_{1}$ is the weight for geometric scattering kernel function $f_{1}$ and $k_{2}$ is the weight for volume scattering kernel function $f_{2}$. Because of its linearity and few parameters (only three), inversion of equation (1) is simple in comparison with many com- plex physical models (Gobron et al., 1997). This semiempirical model can be also applicable to heterogeneous surfaces, and it has been used to generate BRDF dataset for POLDER instrument on ADEOS-I (Lucht and Lewis, 2000).

To check the accuracy of modeling of the bidirectional reflectances, the standard error (SE) is used and computed as follows:

$$
S E=\sqrt{\frac{\sum_{i=1}^{n}\left(\rho_{i}-\hat{\rho}\right)^{2}}{n-p-1}}
$$

where $\rho_{i}$ and $\hat{\rho}$ are the bidirectional reflectances retrieved from SPOT satellite images and the modeled bidirectional reflectances respectively, $n$ is the number of observations and $p$ is the number of parameters (three as shown in Eq. 1) in model (Chang, 1994).

\section{Algorithm of normalization of bidirectional reflectances}

To normalize the bidirectional reflectances from multi-angular SPOT data is to put them to a standardized sun-target-sensor geometry, e.g. solar zenith angle at spring equinox (about $33^{\circ}$ at latitude $25^{\circ}$ ) and nadir view. Normalization of the surface bidirectional reflectances, whose atmospheric effects have been corrected, can be performed as following:

$$
\rho_{n}=\frac{\rho\left(\theta_{s}, \theta_{v}, \phi\right)}{\hat{\rho}\left(\theta_{s}, \theta_{v}, \phi\right)} \rho\left(\theta_{s 0}, \theta_{v 0}, \phi_{0}\right)
$$

where $\rho\left(\theta_{s}, \theta_{v}, \phi\right), \hat{\rho}\left(\theta_{s}, \theta_{v}, \phi\right)$ and $\hat{\rho}\left(\theta_{s 0}, \theta_{v 0}, \phi_{0}\right)$ are the bidirectional reflectances, the modeled bidirectional reflectances and the modeled bidirectional reflectances at standardized solar zenith angle $\theta_{s 0}\left(33^{\circ}\right)$, viewing zenith angle $\theta_{v 0}\left(0^{\circ}\right)$ and relative azimuth angle $\phi_{v 0}\left(0^{\circ}\right)$, respectively. $\rho_{n}$ is the normalized reflectance.

\section{Normalized vegetation indices}

Normalized vegetation indices (VIs) are defined by using normalized reflectances of red and near-IR bands. Normalized NDVI is defined as:

$$
N D V I_{n}=\left(\rho_{n}(N I R)-\rho_{n}(R E D)\right) /\left(\rho_{n}(N I R)+\rho_{n}(R E D)\right)
$$

from its prototype:

$$
N D V I=(\rho(N I R)-\rho(R E D)) /(\rho(N I R)+\rho(R E D)),
$$

and normalized Soil Adjusted Vegetation Index (SAVI) 
Table 1. The solar and viewing geometries of bidirectional SPOT satellite images dataset, where $\theta_{s}, \theta_{v}$ and $\phi$ are solar zenith angle, viewing zenith angle and the absolute value of the relative azimuth angle between solar and viewing azimuth angles, respectively. The retrieved aerosol optical depths in different bands from XS1 to XS3, visibilities and Junge $v$ parameters are also listed

\begin{tabular}{|c|c|c|c|c|c|c|c|c|}
\hline \multirow{2}{*}{ YYMMDD } & \multirow{2}{*}{$\theta_{s}$} & \multirow{2}{*}{$\theta_{v}$} & \multirow{2}{*}{$\phi$} & \multicolumn{3}{|c|}{ Retrieved aerosol optical depth } & \multirow[b]{2}{*}{$(\mathrm{km})$} & \multirow{2}{*}{$\begin{array}{c}\text { Visibility } \\
\text { Junge } v\end{array}$} \\
\hline & & & & XS1 & $\mathrm{XS} 2$ & XS3 & & \\
\hline 981101 & 39.37 & 17.88 & 120.19 & 0.30 & 0.22 & 0.14 & 20.5 & 3.77 \\
\hline 981102 & 41.22 & -19.25 & 53.12 & 0.77 & 0.63 & 0.46 & 5.4 & 3.18 \\
\hline 981103 & 40.86 & 0.49 & 122.98 & 0.84 & 0.68 & 0.48 & 4.9 & 3.26 \\
\hline 981111 & 41.88 & 30.67 & 116.34 & 0.52 & 0.46 & 0.38 & 9.1 & 2.72 \\
\hline 981112 & 43.51 & -7.28 & 56.75 & 0.58 & 0.44 & 0.28 & 8.0 & 3.66 \\
\hline
\end{tabular}

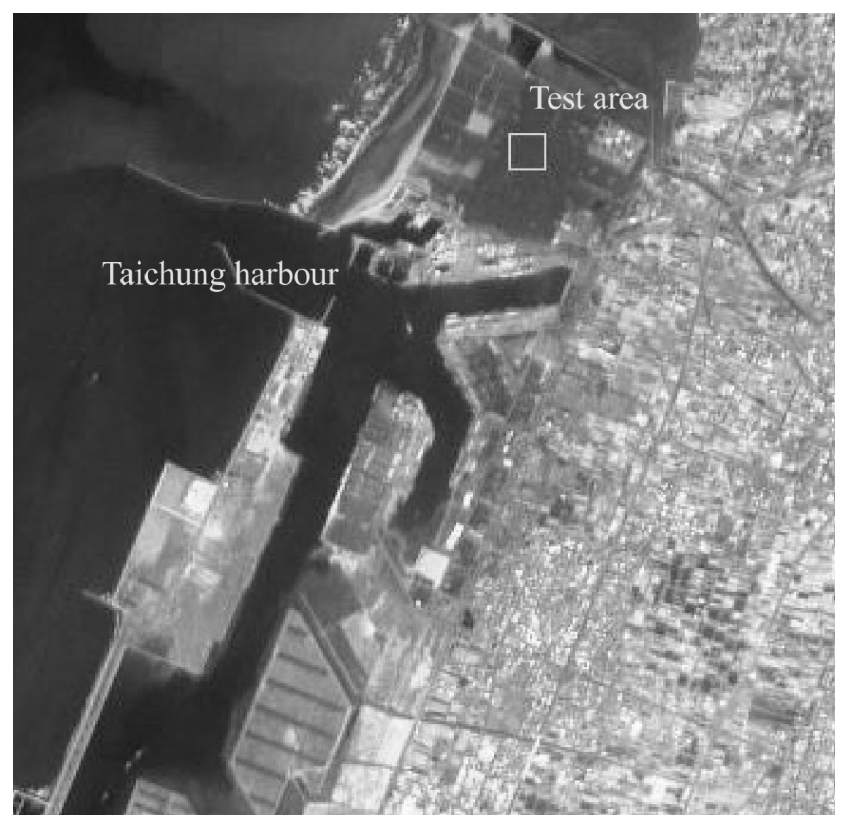

Fig. 1. SPOT image of Taichung harbour scanned on Nov. 12, 1998. The yellow area is the test area where the land cover is Casuarina equisetifolia.

is defined as

$$
\begin{aligned}
S A V I_{n} & =\left(\rho_{n}(N I R)-\rho_{n}(R E D)\right) /\left(\rho_{n}(N I R)+\rho_{n}(R E D)\right. \\
& +L)^{*}(1+L)
\end{aligned}
$$

from its prototype (Huete, 1988):

$$
\begin{aligned}
S A V I & =(\rho(N I R)-\rho(R E D)) /(\rho(N I R)+\rho(R E D)+L) \\
& \times(1+L),
\end{aligned}
$$

where $L$ is a soil-vegetation interaction term to minimize the soil brightness variations. $L$ is set to 0.5 in this study, since it has been demonstrated to work well over a wide range of soil and vegetation amounts in ground measurements (Huete, 1988). To assess the relative variations of bidirectional reflectances, VIs and normalized VIs with viewing zenith angle, coefficient of variation $(\mathrm{CV})$ defined as:

$$
C V=\frac{\sigma}{\mu}
$$

is used, where $\mu$ and $\sigma$ are mean and standard deviation of bidirectional reflectances over different viewing zenith angles. It is expected that normalized vegetation indices, e.g. $N D V I_{n}$ and $S A V I_{n}$, are less varied with viewing zenith angle. However, it is found, as is shown in a later section, that $S A V I$ is similar to $N D V I_{n}$ and $S A V I_{n}$ is also less dependent on viewing zenith angle for trees in this study.

\section{Bidirectional Dataset}

Five SPOT satellite images scanned from Nov. 1 to Nov. 121998 near Taichung harbor in central Taiwan are used to test the normalization algorithm of bidirectional reflectances for multi-angular SPOT satellite images (Table 1). These five images are the only cloudless images received by the receiving station at the Center for Space and Remote Sensing Research in National Central University, Taiwan at the aforementioned temporal ranges. Because these images are scanned within only twelve days, canopies can be reasonably assumed to be invariant. Trees near the harbor are chosen to study the bidirectional reflectance effect of vegetation. Figure 1 shows SPOT image of Taichung harbour scanned on Nov. 12, 1998. Averaged bidirectional reflectance over a $200 \mathrm{~m} \times 200 \mathrm{~m}$ test area (yellow area in Fig. 1) is computed to avoid the canopy mixture at the boundary pixels. The land cover of the test area is Casuarina equisetifolia. The central coordinates in $2^{\circ}$ Transverse Mercater coordinate system are 201625 
$\mathrm{m}$ easting and $2688513 \mathrm{~m}$ northing. The scanned time of the images ranges from 10:30 to 11:00 at local time. The solar zenith angle $\theta_{s}$ differences $\left(\sim 4^{0}\right)$ are small compared to the viewing zenith angle $\theta_{v}\left(-19.3^{\circ} \sim+30.7^{\circ}\right)$. The minus sign indicates image scanned in the antisolar direction, with the sun positioned behind the satellite. The plus sign indicates the forward scattering direction, with the satellite viewing toward the sun. Therefore, the differences of bidirectional reflectances of trees among these five images can be mainly attributed to viewing zenith angle effect.

\section{RESULTS AND DISCUSSION}

The retrieved AOD of every image in the bidirectional SPOT satellite images dataset is shown in Table 1. Since all of the five images seemingly appear to be acquired under clear sky conditions, their atmospheric effects are considered to be uniform. The retrieved AODs range from 0.30 to 0.84 and 0.22 to 0.68 in XS1 and XS2 bands, respectively. The corresponding visibilities range from hazy to clear sky $(4.9 \mathrm{~km} \sim 20.5$ $\mathrm{km})$. The retrieved Junge $v$ parameters range reasonably from 2.72 to 3.77 . Although these retrieved data have not been validated by the con-current sunphotometer measurements, the ability of BACM to retrieve AOD from SPOT satellite images had been shown in Chung-Li city of northern Taiwan as mentioned above. Certainly, it needs more experiments to assess the accuracy of BACM.

By using the retrieved AODs listed in Table 1 as

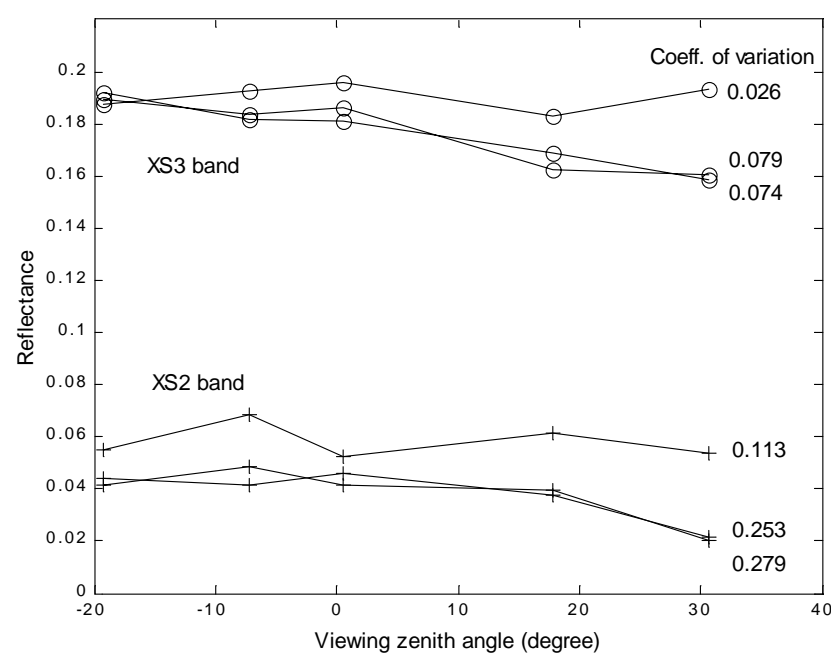

Fig. 2. Atmospheric-corrected reflectance (solid line), model-simulated reflectance (dashed line), normalized reflectance (dashdot line) as a function of viewing zenith angle for trees near Taichung harbor in XS2 and XS3 bands. The numbers in the right side are the coefficient of variation. The upper three lines are in XS3 bands. The lower three lines are in XS2 bands. the inputs of BACM, the atmospheric effect can be corrected and surface bidirectional reflectance can be retrieved. The relationship between surface reflectances, having corrected for atmospheric effect, of trees near Taichung harbor and view angle is depicted in Fig. 2. For clarity, reflectances in XS1 band are not shown. Typical reflectance pattern of vegetation can be obtained after the atmospheric correction. In general, the atmospheric-corrected bidirectional reflectance in backscattering region $\left(\theta_{v}<0\right)$ is larger than that in forescattering region $\left(\theta_{v}>0\right)$. Such trends are consistent with many researchers' measurements (Kimes et al., 1985). The largest NIR reflectance $(0.190)$ is at $\theta_{v}=$ - 19.30 (scene 981102), whereas the smallest NIR reflectance $(0.161)$ is at $\theta_{v}=30.70$ (scene 981111). Although the trees reflectances $(0.060,0.042$ in green (XS1) and red (XS2) bands) on scene 981102 are smaller than those $(0.068,0.048$ in green and red bands) on scene $981112\left(\theta_{v}=-7.30\right)$, the difference is within the error of the algorithm. Overall, the ranges of trees bidirectional reflectances are $0.030 \sim 0.068,0.020 \sim$ $0.048,0.161 \sim 0.190$ in XS1-XS3 band, respectively. The absolute and relative differences are $0.038,0.028$, 0.030 , and $127.7 \%, 140.0 \%, 180.1 \%$ in three bands, respectively. The ratios between off-nadir and nadir trees reflectance range from 0.486 to 1.201 in the visible (XS1 and XS2 bands) and 0.862 to 1.019 in the nearinfrared (XS3 band). Verbrugghe and Cierniewski (1995) also showed that these ratios for cotton crop can range from 0.8 to 1.2 in the visible and 0.8 to 1.12 in the infrared when solar zenith angle varied from $26^{\circ}$ to $73^{\circ}$, for the extreme view angles of $\operatorname{SPOT}\left(-30^{\circ}\right.$ to $\left.+30^{\circ}\right)$ by using SPOT HRV simulation radiometer of CIMEL Electronique Company. Thus, the variation of vegetated surface reflectance to viewing zenith angle is very significant. Therefore, canopy bidirectional reflectances should be modeled and the normalization of these bidirectional effects (especially view angle effect in this dataset) should be performed.

Table 2 shows the retrieved model parameters $\left(k_{0}\right.$, $k_{1}, k_{2}$ ), determination coefficient $R^{2}$ and SE of bidirectional reflectance model of trees from bidirectional dataset (table 1). Although $k_{2}$ (weight of volume scattering component) in XS1 and XS2 bands are negative,

Table 2. Retrieved parameters $\left(k_{0}, k_{1}, k_{2}\right)$, determination coefficient $\boldsymbol{R}^{2}$ and standard error (SE) of bidirectional reflectance model of trees from bidirectional dataset

\begin{tabular}{cccccc}
\hline Band & $k_{0}$ & $k_{1}$ & $k_{2}$ & $R^{2}$ & SE \\
\hline XS1 & 0.1231 & 0.1124 & -0.1124 & 0.81 & 0.013 \\
XS2 & 0.0944 & 0.0935 & -0.1786 & 0.82 & 0.009 \\
XS3 & 0.2194 & 0.0594 & 0.2959 & 0.89 & 0.009 \\
\hline
\end{tabular}


the modeling results are good since $R^{2} \mathrm{~s}$ are all larger than 0.8 and the SEs are around 0.01 in all bands. In fact, the retrieved parameters of a semi-empirical model do not need to lie within physical limits (Li et al., 2001). Roujean et al. (1992) reported that the $R^{2} \mathrm{~s}$ of fitting result between bidirectional reflectance model and surface observations for deciduous forest are 0.52 and 0.32 in the visible and near-infrared. One would not be surprised that the $\mathrm{R}^{2} \mathrm{~s}$ in this study are all higher than the ones for deciduous forest, since the surface observations used by Roujean et al. (1992) are measured in larger ranges of solar $\left(25^{\circ} \sim 63^{\circ}\right)$ and viewing $\left(0^{\circ} \sim 75^{\circ}\right)$ zenith angles, and azimuthal angles $\left(0^{\circ} \sim 180^{\circ}\right)$. The fitting errors in this study may be due to the partial inability of the model (Lucht and Lewis, 2000), the assumption of Lambertian surface of the atmospheric correction model (Hu et al., 1999) such as BACM used here and sparse angular sampling as is typical remote sensing which results in insensitivity of model parameters to the observations (Lucht and Lewis, 2000). Here, only five images are used whose scanned directions are all away from the solar principal plane as SPOT satellite usually does. The retrieved model parameters can be very sensitive to these factors as mentioned above. Nevertheless, the bidirectional effect of vegetation can be reduced by using this bidirectional reflectance model as shown below.

The model-simulated reflectances and the normalized reflectances, using equation (5) at $\theta_{s 0}=33^{\circ}$ and $\theta_{v 0}$ $=0^{\circ}$, are also depicted in Fig. 2. The modeled bidirectional reflectances are well compared with atmosphericcorrected reflectances over the range of viewing zenith

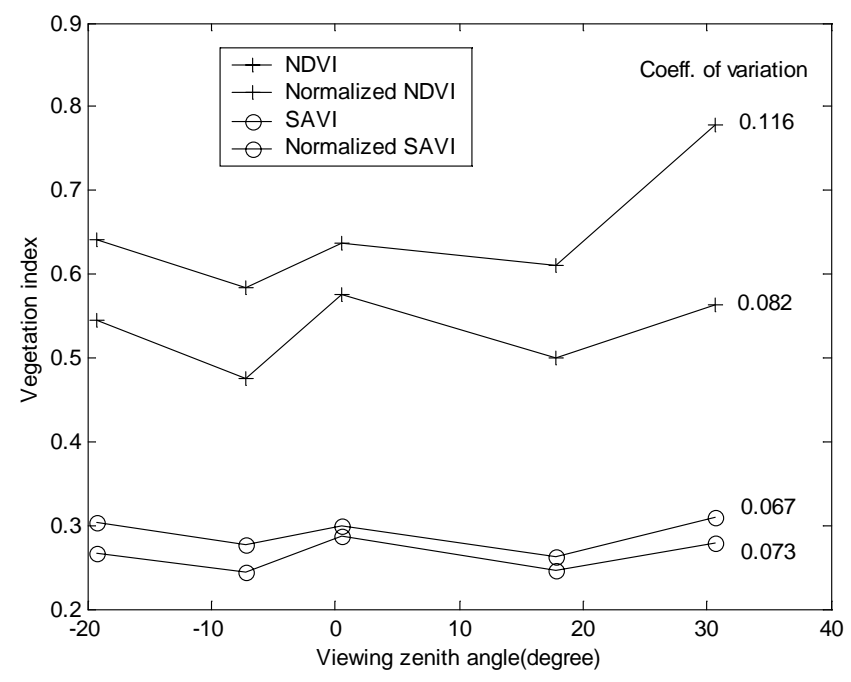

Fig. 3. Vegetation indices of NDVI, normalized NDVI, SAVI and normalized SAVI as a function of viewing zenith angle for trees near Taichung harbor. The numbers in the right side are the coefficients of variation. angle as indicated in table 1 with large $R^{2}$ s and low SEs. The CVs of atmospheric-corrected reflectances are $0.270,0.279$ and 0.079 in XS1, XS2 and XS3 bands, whereas those of normalized reflectances are reduced to $0.111,0.113$ and 0.026 , respectively. One can see that the normalization is less favorable in the visible than in the near-infrared. This is not surprising since the surface signal in the visible is low and more sensitive to the errors of atmospheric correction (Leroy and Roujean, 1994). The CVs of model-simulated reflectances are $0.243,0.253$ and 0.074 , which are nearly equal to those of atmospheric-corrected reflectances in XS1, XS2 and XS3 bands. Although it once again shows the success of the fitting of the bidirectional reflectance model, one should note that this result is only for trees. Further investigation should be done on targets with different vegetation cover percentages. Nevertheless, it seems that one could normalize the bidirectional effect (or correct the viewing zenith angle effect) of the retrieved surface reflectances of multi-angular SPOT satellite images through the use of Roujean's bidirectional reflectance model.

It is interesting to note the dependency of different vegetation indices with viewing zenith angle $\theta_{v}$. Figure 3 describes the relationship between NDVI, SAVI, normalized VIs $\left(\mathrm{NDVI}_{\mathrm{n}}\right.$ and $\left.\mathrm{SAVI} \mathrm{I}_{\mathrm{n}}\right)$ and $\theta_{v}$ for trees near Taichung harbor. NDVI in the extreme forward scattering angle $\left(\theta_{v}=30.7^{\circ}\right)$ is apparently larger than those at other angles, whereas SAVI, $\mathrm{NDVI}_{\mathrm{n}}$ and $\mathrm{SAVI}_{\mathrm{n}}$ are less dependent on $\theta_{v}$. The CVs of NDVI, SAVI, NDVI ${ }_{\mathrm{n}}$ and $\mathrm{SAVI}_{\mathrm{n}}$ are $0.116,0.067,0.082$ and 0.073 , respectively. Normalized vegetation indices such as $\mathrm{NDVI}_{n}$ and $\mathrm{SAVI}_{\mathrm{n}}$ (formulated by standardized reflectances in referenced solar angle $\left(\theta_{s}=33^{\circ}\right)$ and nadir view angle) are by their nature expected to be less varied with $\theta_{v}$, whereas the $\mathrm{CV}$ of SAVI (VI adjusted for correction of background soil), is even the smallest among the four VIs. This differs from the studies for sparse grassland canopies (Huete et al., 1992) and alfalfa (Epiphanio and Huete, 1995). For sparse grassland canopies, SAVI was symmetric about nadir and could be corrected by a cosine function of $\theta_{v}$, whereas it decreased as the viewing direction moved from antisolar to forward scattering direction for alfalfa. The $L$ value adjusted in SAVI was (as this study) set to 0.5 for different vegetation cover of canopies. In addition to different canopies studied, one of the reasons of the different results may be attributed to the sampling geometry of bidirectional SPOT data considered here. It should be emphasized that the viewing directions of the bidirectional SPOT dataset (table 1) are away from the solar principal plane, while measurements are taken in the principal plane for studies of Huete et al. (1992) and Epiphanio and Huete (1995). The bidirectional effect is related to the relative 
proportions of sunlit, shadowed soil and plant surfaces, and it is strongest along the principal plane and weaker along the non-principal plane. By using the soil-adjusted $L$ factor, SAVI may be less dependent on viewing angle than NDVI, particularly along the non-principal plane. The other reason may be also attributed to the errors of retrieved bidirectional reflectances through atmospheric correction. One should keep in mind that the errors of the atmospheric correction model BACM used here are 0.04 , which may induce uncertainties on the surface reflectances, the regressed bidirectional reflectance model and then the computed VIs. That is to say, this result may be misleading due to the errors of BACM. Therefore, more studies should be done to decide whether SAVI is less sensitive to $\theta_{v}$ than NDVI, $\mathrm{NDVI}_{\mathrm{n}}$ and $\mathrm{SAVI}_{\mathrm{n}}$. One should use a more accurate atmospheric correction model, e.g. error about 0.01 . Positively, it can also be justified by using the surface observations measured in different $\theta_{s}, \theta_{v}, \phi$ to prevent the possible errors induced from the atmospheric correction. Further studies should also be undertaken for different canopies in different seasons (thus, different relative azimuth angle) for SPOT data. Nevertheless, normalized vegetation indices such as $\mathrm{NDVI}_{\mathrm{n}}$ and $\mathrm{SAVI}_{\mathrm{n}}$ are able to greatly reduce the view angle effect of NDVI.

\section{CONCLUSIONS}

In this study, a normalization scheme of bidirectional reflectances and normalized vegetation indices are developed for short-term multi-angular SPOT data. Five SPOT images scanned within twelve days are used. The results show that the variation of bidirectional reflectance of trees to viewing zenith angle is very significant. Their relative differences are $127.7 \%$, $140.0 \%, 180.1 \%$ in XS1, XS2 and XS3 bands, respectively. The proposed normalization scheme can satisfactorily correct the viewing zenith angle effect of bidirectional reflectances of trees. The CVs of bidirectional reflectances of trees are greatly reduced from $0.270,0.279$ and 0.079 to $0.111,0.113$ and 0.026 after normalization in XS1, XS2 and XS3 bands, respectively. The proposed $\mathrm{NDVI}_{\mathrm{n}}$ and $\mathrm{SAVI}_{\mathrm{n}}$ are also able to greatly correct the viewing zenith angle effect compared with NDVI. The CVs of $\mathrm{NDVI}_{\mathrm{n}}$ and $\mathrm{SAVI}_{\mathrm{n}}$ are 0.082 and 0.073 , which are also smaller than that of NDVI (0.116). Meanwhile, the CV of SAVI is 0.067 , which is even less than those of $\mathrm{NDVI}_{\mathrm{n}}$ and $\mathrm{SAVI}_{\mathrm{n}}$. This differs from the results found by Huete et al. (1992) and Epiphanio and Huete (1995), where measurements are taken in the principal plane. This may be due to the effectiveness of SAVI in reducing the soil dependence and thus leading to less dependency on viewing zenith angle. This may also be attributed to the errors of atmospheric correction model BACM. Similar studies should be done by using either more accurate atmospheric correction model, e.g. error about 0.01 , or ground measurements. Certainly, more studies should also be done to justify the ability of SAVI to correct the viewing zenith angle effect in different azimuthal planes for different targets with different vegetation cover percentages. In the near future, the normalization of long-term (e.g., annual) multi-temporal SPOT data will also be studied

\section{ACKNOWLEDGEMENTS}

This study was financially supported by the National Science Council of the Republic of China (grant No. NSC91-2212-E-265-001).

\section{REFERENCES}

1. Asner, G.P., Braswell, B.H., Schimel, D.S., and Wessman, C. A., "Ecological Research Needs from Multiangle Remote Sensing Data," Remote Sens. Environ., Vol. 63, pp. 155-165 (1998).

2. Chang, J.B., Statistics, San-Ming Co., Taipei, pp. 64-66 (1994). (in Chinese)

3. Deering, D.W., Eck, T.F., and Grier, T., "Shinnery Oak Bidirectional Reflectance Properties and Canopy Model Inversion," IEEE Trans. Geosci. Remote. Sens., Vol. 30, No. 2, pp. 339-348 (1992).

4. Duchemin, B., Berthelot, B., Dedieu, G., Leroy, M., and Maisongrande, P., "Normalization of Directional Effects in 10-day Global Synthesis Derived from VEGETATION/SPOT:II. Validation of An Operational Method on Actual Data Sets," Remote Sens. Environ., Vol. 81, pp. 101-113 (2002).

5. Epiphanio, J.C.N. and Huete, A.R., "Dependence of NDVI and SAVI on Sun/Sensor Geometry and Its Effect on fAPAR Relationships in Alfalfa," Remote Sens. Environ., Vol. 51, pp. 351-360 (1995).

6. Gobron, N., Pinty, B., Verstraete, M.M., and Govaerts, Y., "A Semi-Discrete Model for the Scattering of Light by Vegetation," J. Geophys. Res., Vol. 102, pp. 94319466 (1997).

7. Gupta, A., Lim, H., Huang, X., and Chen, P., "Evaluation of Part of the Mekong River Using Satellite Imagery," Geomorph., Vol. 44, pp. 221-239 (2002).

8. Holben, B.N., Eck, T.F., Slutsker, I., Tanre, D., Buis, J. P., Setzer, A., Vermote, E., Reagan, J.A., Kaufman, Y., Nakajima, T., Lavenu, F., Jankowiak, I., and Smirnov, A., "AERONET - A Federated Instrument Network and Data Archive for Aerosol Characterization," Remote Sens. Environ., Vol. 66, pp. 1-16 (1998).

9. Hu, B., Lucht, W., and Strahler, A.H., "The Interrelationship of Atmospheric Correction of Reflectances and 
Surface BRDF Retrieval: A Sensitivity Study," IEEE Trans. Geosci. Remote Sens., Vol. 37, No. 2, pp. 724-738 (1999).

10. Hu, B., Lucht, W., and Strahler, A.H., "Surface Albedos and Angle-Corrected NDVI from AVHRR Observations of South America," Remote Sens. Environ., Vol. 71, pp. 119-132 (2000).

11. Huete, A.R., "A Soil Adjusted Vegetation Index (SAVI)," Remote Sens. Environ., Vol. 25, pp. 295-309 (1988).

12. Huete, A. R., Hua, G., Qu, J., Chebouni, A., and van Leeuwen, W., "Normalization of Multidirectional red and NIR Reflectances with the SAVI," Remote Sens. Environ., Vol. 40, pp. 1-20 (1992).

13. Huete, A., Justice, C., and van Leeuwen, W., MODIS Vegetation Index (MOD13): Algorithm Theoretical Basis Document, NASA EOS MODIS Doc (version 3), pp. 910 (1999).

14. Kalluri, S.N.V., Zhang, Z., Jaja, J., Liang, S., and Townshend, J. R. G., "Characterizing Land Surface Anisotropy from AVHRR Data at a Global Scale Using High Performance Computing," Int. J. Remote Sens., Vol. 22, No. 11, pp. 2171-2191 (2001).

15. Kimes, D.S., Newcomb, W.W., Tucker, C.J., Zonneveld, I.S., van Wijngaarden, W., de Leeuw, J., and Epema, G. F., "Directional Reflectance Factor Distributions for Cover Types of Northern Africa," Remote Sens. Environ., Vol. 18, pp. 1-19 (1985).

16. Leroy, M. and Hautecoeur, O., "Anisotropy-Corrected Vegetation Indexes Derived from POLDER/ADEOS," IEEE Trans. Geosci. Remote Sens., Vol. 37, No. 3, pp. 1698-1708 (1999).

17. Leroy, M. and Roujean, J.L., "Sun and View Angle Corrections on Reflectances Derived from NOAA/ AVHRR Data," IEEE Trans. Geosci. Remote Sens., Vol. 32, No. 3, pp. 684-97 (1994).

18. Li, X., Gao, F., Wang, J., and Strahler, A.H., "A Priori Knowledge Accumulation and Its Application to Linear BRDF Model Inversion,” J. Geophys. Res., Vol. 106, No. D11, pp. 11925-11935 (2001).

19. Liu, C.H. and Lin, J.F., "Development of a WindowBased Atmospheric Correction Information System for Remotely Sensed Data," J. Photogrammet. Remote Sensing, Vol. 8, No. 2, pp. 81-92 (2003). (in Chinese)

20. Liu, C.H. and Vermote, E.F., "A Reflectance Retrieval Algorithm for Landsat TM Satellite Image," The 21st Asian Conference on Remote Sensing, December 4-8,
Taipei, Taiwan, pp. 522-526 (2000).

21. Liu, C.H., Yang, C.M., and Liu, G.R., "Accuracies Assessment of the Atmospheric Correction Model and Retrieved Rice Reflectance for SPOT Satellite Images," Chinese J. Agromet., Vol. 8, pp. 1-10 (2001). (in Chinese)

22. Lucht, W. and Lewis, P., "Theoretical Noise Sensitivity of BRDF and Albedo Retrieval from the EOS-MODIS and MISR Sensors with Respect to Angular Sampling," Int. J. Remote Sens., Vol. 21, No. 1, pp. 81-98 (2000).

23. Nilsen, L., Elvebakk, A., Brossard, T., and Joly, D., "Mapping and Analysing Arctic Vegetation: Evaluating a Method Coupling Numerical Classification of Vegetation Data with SPOT Satellite Data in a Probability Model," Int. J. Remote Sens., Vol. 20, No. 15-16, pp. 2947-2977 (1999).

24. Roujean, J.L., Leroy, M., and Deschamps, P.Y., “A Bidirectional Reflectance Model of the Earth's Surface for the Correction of Remote Sensing Data," J. Geophys. Res., Vol. 97, No. D18, pp. 20455-22468 (1992).

25. Strahler, A.H., Townshend, J., Muchoney, D., Borak, J., Friedl, M., Gopal, S., Hyman, A., Moody, A., and Lambin, E., MODIS Land Cover and Land Cover Change: Algorithm Technical Basis Document, NASA EOS MODIS Doc., version 4.1, pp. 1-102 (1996).

26. Turner, M.D. and Congalton, R.G., "Classification of Multi-Temporal SPOT-XS Satellite Data for Mapping Rice Data on a West African Floodplain," Int. J. Remote Sens., Vol. 19, No. 1, pp. 21-41 (1998).

27. Ustin, S.L. and Xiao, Q.F., "Mapping Successional Boreal Forests in Interior Central Alaska," Int. J. Remote Sens., Vol. 22, No. 9, pp. 1779-1787 (2001).

28. Verbrugghe, M. and Cierniewski, J., "Effects of Sun and View Geometries on Cotton Bidirectional Reflectance: Test of a Geometrical Model," Remote Sens. Environ., Vol. 54, pp. 189-97 (1995).

29. Walthall, C.L., Norman, J.M., Welles, J.W., Campbell, G., and Blad, B.L., "Simple Equation to Approximate the Bidirectional Reflectance from Vegetated Canopies and Bare Soil Surfaces," Appl. Opt., Vol. 24, No. 3, pp. 383-387 (1985).

30. Wanner, W., Strahler, A.H., Hu, B., Lewis, P., Muller, J. P., Li X., Barker-Schaaf, C.L., and Barnsley, M.J., "Global Retrieval of Bi-Directional Reflectance and Albedo Over Land from EOS MODIS and MISR Data: Theory and Algorithm," J. Geophys. Res., Vol. 102, No. D14, pp.17143-17161 (1997). 